\title{
Economic Integration and Growth
}

\author{
Shawn Cole ${ }^{1} \cdot$ Silvana Tenreyo $^{2}$
}

Published online: 25 August 2021

(C) International Monetary Fund 2021

\section{Challenges and opportunities...}

Global economic growth and economic integration suffered major setbacks in 2020-21 owing to the Coronavirus crisis and the huge strains it put on people, companies and governments all around the world. Trade restrictions and global supply*_ chain disruptions in particular became recurrent challenges during the pandemic. But even before the crisis, trade tensions and constraints to economic integration threatened to limit many countries' abilities to reap the benefits of globalization. Against this background, the IMF Economic Review (IMFER) commissioned a special issue focused on the theme of "Economic Integration and Growth." While the accompanying conference, which was to have taken place in Rabat, Morocco, with the cooperation of Bank Al-Maghrib, could not be held, we are delighted to introduce the articles in this volume, summarized below.

The first paper, "Infrastructure Investment and Labor Monopsony Power" by Wyatt J Brooks (Arizona State University), Joseph P Kaboski (University of Notre Dame and NBER), Illenin Kondo (Federal Reserve Bank of Minneapolis), Yao Amber Li (Hong Kong University of Science and Technology), and Wei Qian (Shanghai University of Finance and Economics), examines how transportation integration affects local labor markets. Exploiting variation induced by the construction of the "Golden Quadrilateral" road system in India, they demonstrate manufacturing employers in markets closer to the highway system that have reduced market power relative to employers in markets that are less connected. Importantly, they can separately identify changes in both monopsony power and output markups, and find highway construction is pro-competitive in both input and output markets. The net effect is to increase the labor share of income by approximately 2 percentage points.

The second paper, "Trade Integration, Global Value Chains, and Capital Accumulation" by Michael Sposi (Southern Methodist University), Kei-Mu Yi (University of Houston), and Jing Zhang (Federal Reserve Bank of Chicago), presents a

Shawn Cole

scole@hbs.edu

1 Harvard Business School, Boston, MA, USA

2 London School of Economics, London, UK 
framework to study the dynamic impact of global trade and fragmentation of production that had been accompanied by significant income convergence in many emerging economies. The paper builds a dynamic two-country model featuring sequential, multi-stage production, and capital accumulation. As trade costs decline over time, global-value-chain (GVC) trade expands across countries, particularly more in the faster growing country, consistent with the empirical pattern. Via HeckscherOhlin forces, GVC trade can generate back-and-forth feedback between comparative advantage and capital accumulation (growth). Moreover, GVC trade increases both steady-state and dynamic gains from trade. At the current juncture, the model can help us assess the consequences that reversing those globalization trends might have on income and welfare.

The third paper in the volume, "Entry and exit of informal firms and development" by Brian McCaig (Wilfrid Laurier University) and Nina Pavcnik (Dartmouth College), provides new insights into the economics of non-farm informal businesses in developing countries. Non-farm informal businesses comprise the majority of the firm distribution in developing countries. The paper documents a number of novel stylized facts about entry and exit of informal, non-farm firms using a nationally representative panel dataset over 15 years and across regions with varying levels of local economic development in Vietnam. First, informal businesses exhibit annual rates of entry and exit of around 15-19\%. Entry and exit rates are similar and highly correlated at a point in time, within industries, and within regions, and they both decline over time and across space with economic development. Second, although market selection influences which firms survive, entry and exit has little net effect on aggregate (revenue) productivity or hiring of workers outside the household. Third, the large overlap in revenue of entering and exiting informal businesses and the high correlation between entry and exit rates are related to the education of owners and their economic activities before and after operating an informal business. Informal business owners are less educated on average than wage workers in the formal sector, but more educated than agricultural workers. The transitions in and out of operating an informal business reflect the underlying structure of economic activities of the working age population, with education gaps also playing a role. The most common transition into non-farm businesses is to and from self-employment in agriculture. The likelihood of this transition declines with economic development, highlighting the role of net entry from agriculture into informal non-farm businesses in structural change.

Greater integration of women into the labor force is perhaps one of the most powerful levers of growth in many emerging markets. This issue concludes with a Policy Corner article, titled "Social Norms as a Barrier to Women's Employment in Developing Countries" by Seema Jayachandran (Northwestern University). The article starts with a discussion of the relationship between economic growth and female employment, pointing out that a significant amount of variation is unexplained by economic factors, leaving an important role for norms in determining labor force participation. The article examines evidence of the role of several gender-related social norms, and discusses evaluations of interventions designed to overcome such barriers, both by helping women work around a norm, as well as by changing norms. Jayachandran concludes that both approaches can be successful, and 
that implementing supportive policies could substantially narrow gender gaps in the labor market.

We hope that you will enjoy reading this issue. The topics covered are of fundamental importance to the functioning of the global economics system, and speak particularly to the challenges and opportunities present in many emerging markets. Taken together, these papers present novel empirical evidence on labor market integration, the creation and destruction of informal firms, as well as new insights on the causes and consequences of the increasing dispersion of global value chains, and sound policy guidance on increasing female labor force participation.

We thank all the authors for their valuable contributions, and the referees for making the papers even better. Finally, we thank Tracey Lookadoo for ensuring a smooth process during challenging times, and Emine Boz, Andrei Levchenko, Prachi Mishra, and Linda Tesar, along with the IMFER for giving us the opportunity to create this issue.

Shawn Cole and Silvana Tenreyo

Guest Editors, IMF Economic Review

Publisher's Note Springer Nature remains neutral with regard to jurisdictional claims in published maps and institutional affiliations. 